\title{
How to improve the care of patients with acute kidney injury
}

\author{
Rinaldo Bellomo ${ }^{1 *}$, Suvi T. Vaara ${ }^{2,3}$ and John A. Kellum ${ }^{4}$
}

(C) 2017 Springer-Verlag Berlin Heidelberg and ESICM

\section{Introduction}

Almost all patients treated in adult general intensive care units (ICUs) carry an increased risk for acute kidney injury (AKI). This syndrome of abruptly decreased glomerular filtration rate was diagnosed in over $50 \%$ of critically ill patients in a multinational cohort study and is associated with a variety of adverse short-term [1] and long-term outcomes [2, 3]. Therefore, being aware of AKI and staying up-to-date regarding the implications of latest clinical research are relevant to all intensivists. This issue of Intensive Care Medicine provides a comprehensive collection of the latest advances in the field of AKI research as well as expert opinions and reviews covering topics about AKI in specific populations $[4,5]$ as well as key elements of AKI management $[6,7]$. This set of papers combines state-of-the-art knowledge and new ideas to improve current clinical practice and represents "required reading" for practicing intensivists with all major aspects of this syndrome being analyzed and reviewed in depth.

The unified definition of AKI [8], although not without challenges [9], has resulted in better understanding of epidemiology and promoted standardization of trial endpoints [10]. Moreover, significant effort has been invested in the search for predictive biomarkers of AKI. Although initial results were disappointing [11], failures in the biomarker field have increased our understanding of this syndrome and, more recently, cell cycle arrest biomarkers seem to hold greater promise for better patient care [12]. At the same time, animal research has revealed the potentially different pathophysiology behind septic AKI. Such understanding may allow advances in drug

\footnotetext{
*Correspondence: rinaldo.bellomo@austin.org.au

${ }^{1}$ Department of Intensive Care and Department of Medicine, Austin

Hospital, Studley Rd, Heidelberg, VIC 3084, Australia
}

Full author information is available at the end of the article development and some promising agents are currently being tested in septic AKI [4].

Adequate identification of patients with an increased risk for AKI is a key element in the chain of prevention of AKI. Flechet et al. report encouraging results from their analysis in the EPaNIC database showing that models comprising routinely collected data outperformed neutrophil gelatinase-associated lipocalin in predicting AKI [13]. Furthermore, a challenge for any predictive tool is to improve care. Meersch et al. have recently used cell cycle arrest biomarkers in cardiac surgical patients to define subjects with high risk and randomized them either to a treatment bundle aiming at avoiding further nephrotoxic insults and optimization of the hemodynamic status or to standard care. This approach resulted in a lower rate of developing AKI, but the study was underpowered to examine renal recovery or mortality rates [12]. This single-center trial turns a new page in biomarker research to biomarker-directed management protocols for AKI prevention and treatment and should hopefully prompt others to study interventions using enrichment strategies.

\section{Management of AKI}

Fluid therapy is administered to all ICU patients. Patients with oliguric AKI are at especially high risk of developing fluid overload that associates with increased mortality. Therefore, understanding when additional fluids can be beneficial in oliguria and when they can cause harm is a key element in the management of these patients [14]. Strategies that deliver more fluids are clearly not superior to strategies that deliver less fluid either for prevention or resolution of AKI in the setting of septic shock. In addition, knowledge of different fluid types and their potential harm has greatly increased, and the review by Perner et al. provides comprehensive insights into these issues [7].

\section{实


About one-fifth of patients with AKI commence renal replacement therapy (RRT) [1]. The optimal time to start RRT in the absence of emergency indications remains uncertain, but the STARRT-AKI trial (NCT02568722) is now well underway and is likely to bring high-level evidence to the field along with other recent trials that are discussed in the review summarizing the state-of-the-art for management of RRT by Bagshaw et al. [6]. The issue of optimal timing for the discontinuation of RRT also lacks definitive evidence, but Forni et al. provide practical insights into the topic in their viewpoint on this issue. Moreover, in future we may be able to provide continuous RRT that uses dynamic biofeedback loops from data regarding fluid balance and blood chemistry to provide an optimal dialysis dose [15].

\section{Follow-up}

Adverse consequences of AKI on long-term renal function are becoming increasingly known, although studies prospectively assessing renal function of AKI survivors are few. The recovery process from AKI can be fluctuating with different scenarios. Even after initial recovery, patients remain at increased risk of developing chronic kidney disease. Therefore, all patients exposed to RRT may benefit from nephrologist follow-up to address treatable and avoidable risk factors and to minimize potential further worsening of renal function $[2,3]$.

\section{Clinical trials}

Despite doubling of AKI-related citations during the last 10 years, many key areas still lack good-quality evidence and treatment recommendations are often based on expert opinions [16]. However, active research has challenged many long-standing beliefs and provided evidence-based guidance in key areas such as, for example, the dose of RRT $[6,17]$. Issues such as AKI care bundles, RRT discontinuation, fluid restriction and removal, novel pathophysiology-based pharmacological interventions, recruitment of renal functional reserve [18], and use of chloride-rich fluids in heterogeneous ICU populations are among the proposed top ten trials to be conducted within the next 10 years [17]. Hopefully, these and other trials will bring advances in the field of AKI management that can be translated into improvements in patient-centered outcomes worldwide.

\section{Conclusions}

Our knowledge about how to diagnose, prevent, and treat AKI has rapidly evolved during the last decade. Figure 1 summarizes current and potentially emerging means to

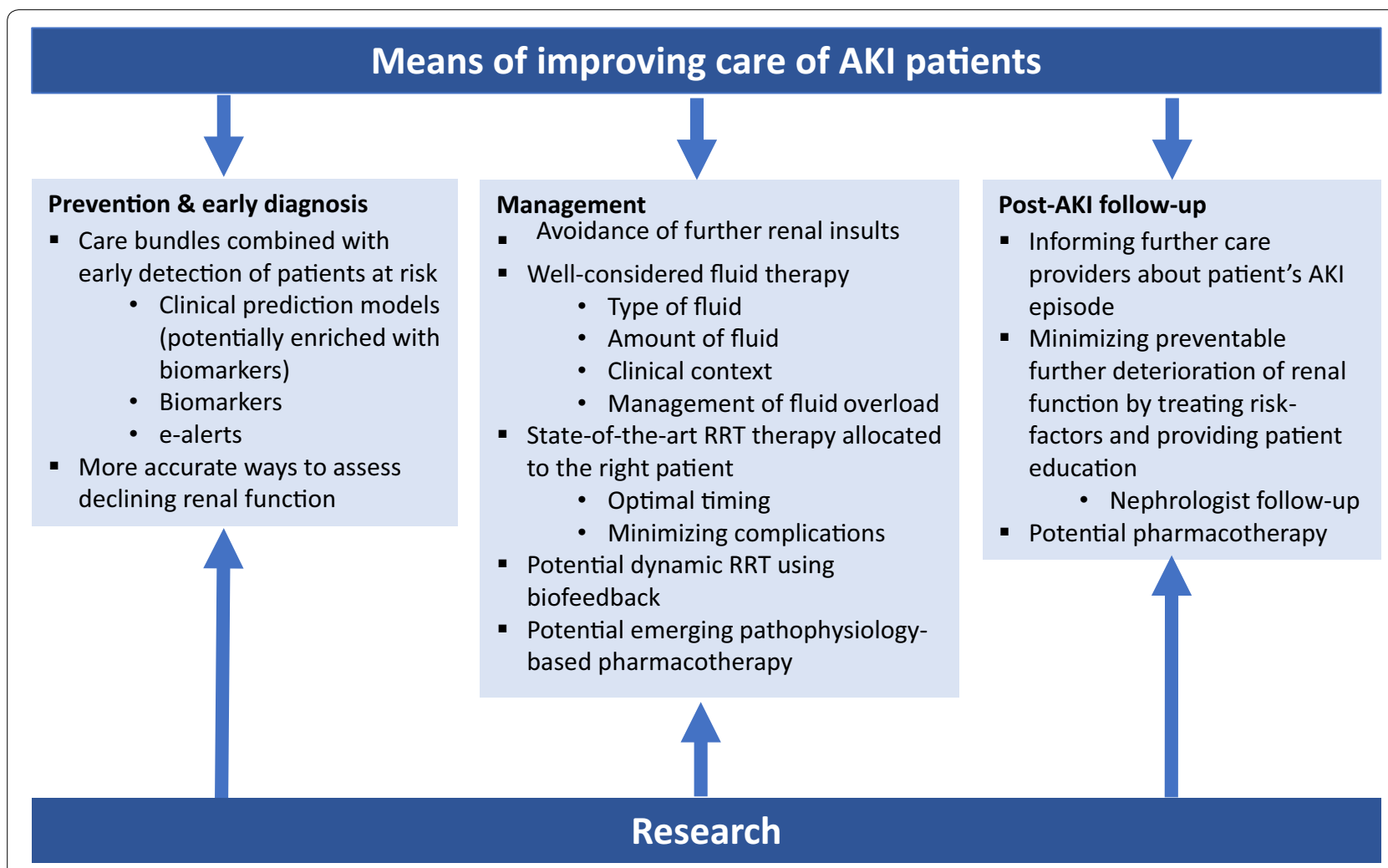

Fig. 1 Means of improving care of patients with acute kidney injury. AKl acute kidney injury, RRT renal replacement therapy 
improve patient care in this field. Hopes are high for the development of more accurate and practical methods to measure deteriorating renal function thus allowing earlier diagnosis and enabling frequent and more accurate monitoring. Earlier diagnosis would allow prevention of further deterioration, especially if pharmacotherapy to prevent and treat AKI becomes available. However, before these potential interventions become available for daily clinical practice, all clinicians can still do their best to detect AKI, establish its etiology, avoid further renal insults, optimize fluid therapy and hemodynamics, provide high-quality RRT, and make sure that information about the AKI episode is conveyed to colleagues taking care of the patient after ICU discharge. The well-being of AKI patients depends on such awareness, knowledge, clinical skills, and diligence. Our patients deserve no less.

\section{Author details \\ 1 Department of Intensive Care and Department of Medicine, Austin Hospital, Studley Rd, Heidelberg, VIC 3084, Australia. ${ }^{2}$ Department of Intensive Care, Austin Hospital, Melbourne, Australia. ${ }^{3}$ Division of Intensive Care Medicine, Department of Anesthesiology, Intensive Care and Pain Medicine, University of Helsinki and Helsinki University Hospital, Helsinki, Finland. ${ }^{4}$ Department of Critical Care Medicine, Center for Critical Care Nephrology, University of Pittsburgh, Pittsburgh, PA, USA.}

\section{Acknowledgements}

STV is supported by a Fellowship grant from Sigrid Juselius Foundation.

\section{Compliance with ethical standards}

\section{Conflicts of interest}

The authors declare no conflicts of interests in relation to this article.

Received: 18 April 2017 Accepted: 22 April 2017

Published online: 8 May 2017

\section{References}

1. Hoste EA, Bagshaw SM, Bellomo R, Cely CM, Colman R, Cruz DN, Edipidis K, Forni LG, Gomersall CD, Govil D, Honore PM, Joannes-Boyau O, Joannidis M, Korhonen AM, Lavrentieva A, Mehta RL, Palevsky P, Roessler E, Ronco C, Uchino S, Vazquez JA, Vidal Andrade E, Webb S, Kellum JA (2015) Epidemiology of acute kidney injury in critically ill patients: the multinational AKI-EPI study. Intensive Care Med 41:1411-1423

2. Bell M, Chawla LS, Wald R (2017) Understanding renal recovery. Intensive Care Med. doi:10.1007/s00134-017-4773-5

3. Forni LG, Darmon M, Ostermann M, Oudemans-van Straaten HM, Pettilä V, Prowle JR, Schetz M, Joannidis M (2017) Renal recovery after acute kidney injury. Intensive Care Med. doi:10.1007/s00134-017-4809-x
4. Bellomo R, Kellum JA, Ronco C, Wald R, Martensson J, Maiden M, Bagshaw SM, Glassford NJ, Lankadeva Y, Vaara ST, Schneider A (2017) Acute kidney injury in sepsis. Intensive Care Med. doi:10.1007/s00134-017-4755-7

5. Darmon M, Ostermann M, Cerda J, Dimopoulos MA, Forni LG, Hoste E, Legrand M, Lerolle N, Rondeau E, Schneider A, Souweine B, Schetz M (2017) Diagnostic work-up and specific causes of acute kidney injury. Intensive Care Med. doi:10.1007/s00134-017-4799-8

6. Bagshaw SM, Darmon M, Ostermann M, Finkelstein FO, Wald R, Tolwani AJ, Goldstein SL, Gattas DJ, Uchino S, Hoste EA, Gaudry S (2017) Current state of the art for renal replacement therapy in critically ill patients with acute kidney injury. Intensive Care Med. doi:10.1007/s00134-017-4762-8

7. Perner A, Prowle J, Joannidis M, Young P, Hjortrup PB, Pettilä V (2017) Fluid management in acute kidney injury. Intensive Care Med. doi:10.1007/ s00134-017-4817-x

8. Kidney Disease: Improving Global Outcomes (KDIGO) Acute Kidney Injury Work Group (2012) KDIGO clinical practice guideline for acute kidney injury. Kidney Int Suppl 2:1-138

9. Schetz M, Schortgen F (2017) Ten shortcomings of the current definition of AKI. Intensive Care Med. doi:10.1007/s00134-017-4715-2

10. Kellum JA, Zarbock A, Nadim MK (2017) What endpoints should be used for clinical studies in acute kidney injury? Intensive Care Med. doi:10.1007/s00134-017-4732-1

11. Van Massenhoven J, Ostermann M, Kielstein J (2017) Have renal biomarkers failed in acute kidney injury? Yes. Intensive Care Med. doi:10.1007/ s00134-017-4759-3

12. Meersch M, Schmidt C, Hoffmeier A, Van Aken H, Wempe C, Gerss J, Zarbock A (2017) Prevention of cardiac surgery-associated AKI by implementing the KDIGO guidelines in high risk patients identified by biomarkers: the PrevAKI randomized controlled trial. Intensive Care Med. doi:10.1007/s00134-016-4670-3

13. Flechet M, Guiza F, Schetz M, Wouters P, Vanhorebeek I, Derese I, Gunst J, Spriet I, Casaer M, Van den Berghe G, Meyfroidt G (2017) AKIpredictor, an online prognostic calculator for acute kidney injury in adult critically ill patients: development, validation and comparison to serum neutrophil gelatinase-associated lipocalin. Intensive Care Med. doi:10.1007/ s00134-017-4678-3

14. Schortgen F, Schetz M (2017) Does this critically ill patient with oliguria need more fluids, a vasopressor, or neither? Intensive Care Med. doi:10.1007/s00134-017-4744-x

15. Cerda J, Baldwin I, Honore PM, Villa G, Kellum JA, Ronco C (2016) Role of technology for the management of AKI in critically ill patients: from adoptive technology to precision continuous renal replacement therapy. Blood Purif 42(3):248-265

16. Lameire N, Vanmassenhove J, Lewington A (2017) Did KDIGO guidelines on acute kidney injury improve patient outcome? Intensive Care Med. doi:10.1007/s00134-017-4740-1

17. Pickkers P, Ostermann M, Joannidis M, Zarbock A, Hoste E, Bellomo R, Prowle J, Darmon M, Bonventre JV, Forni L, Bagshaw SM, Schetz M (2017) The intensive care medicine agenda on acute kidney injury. Intensive Care Med. doi:10.1007/s00134-017-4687-2

18. Ronco C, Bellomo R, Kellum J (2017) Understanding renal functional reserve. Intensive Care Med. doi:10.1007/s00134-017-4691-6 